\title{
A VINGANÇA DA LÍRICA
}

Textos de Ana Chiara/imagens Artur de Vargas Giorgi 


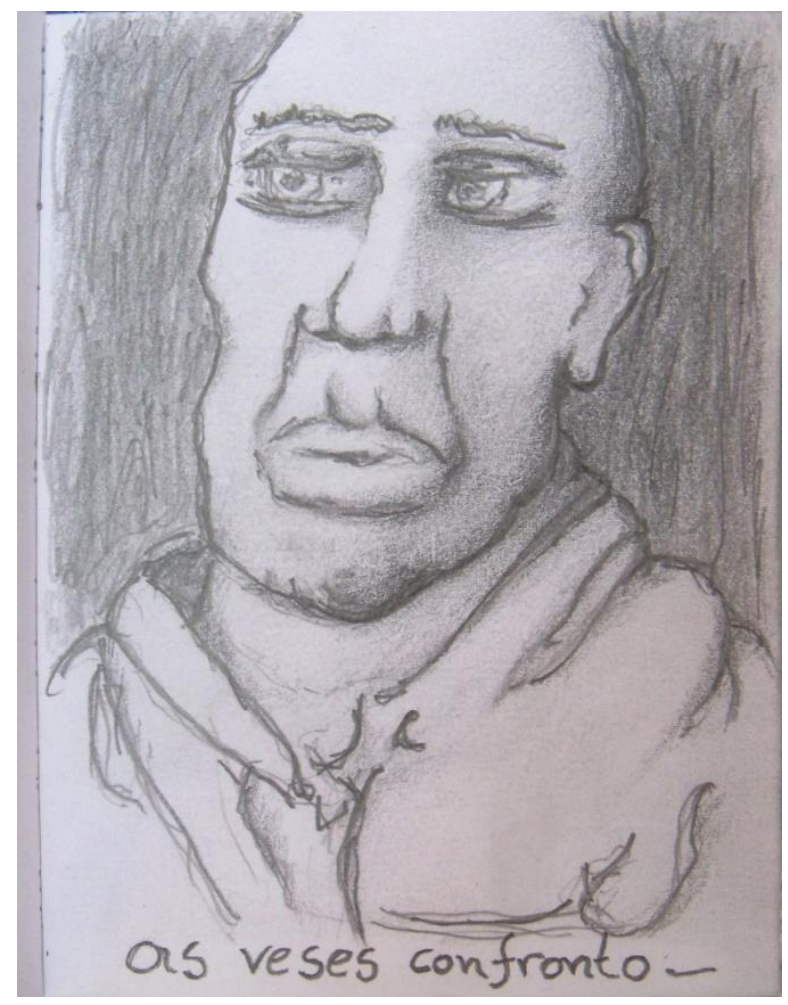

\section{Pulmões}

Poeta lírico respira no espelho

$O$ ar de seus pulmões

não brilha, embaça... 
hérnia de hiato

Passou da hora,

o poeta engoliu a lírica

agora vomita, baba,

bílis, blá, blá, blá. 




hipocentauro pistoleiro

Como se disso o mundo dependesse, $O$ poeta lírico pensa cavalgar o hipocentauro da poesis "qualcuno è um romântico irreversible: la cibernética non cambiarà la sua mente" ${ }^{1}$ 


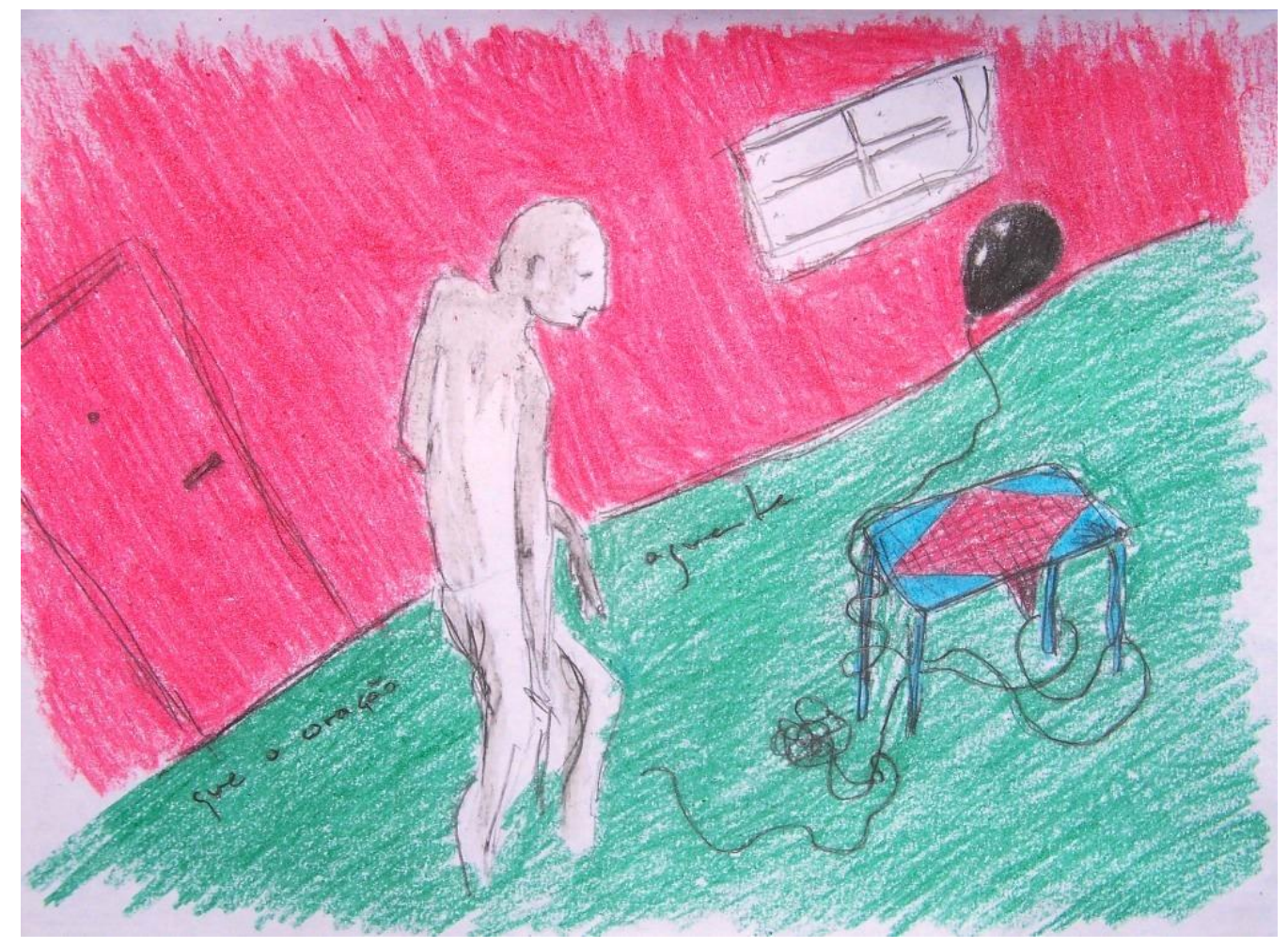

\section{Sublinguae}

Isordil

não acalma

o coração taquicárdico do poeta, inseparável do grande lamento

ele se sente um pequenino Deus ${ }^{2}$ 


\section{emblemas}

Presa à cosmética

da elegia,

da queixa, da gueixa,

máscara com cílios postiços:

a língua do poeta. 


\section{Lírica responde (cena do drama poético)}

Trouxeste a chave, Cavaleiro da Triste Figura?

Sim, ele se apressa a responder, cãozinho amestrado estende a pata....

- Lamento, mas está enferrujada

sua máquina de fazer versos grimpou,

superficial e pesada... 


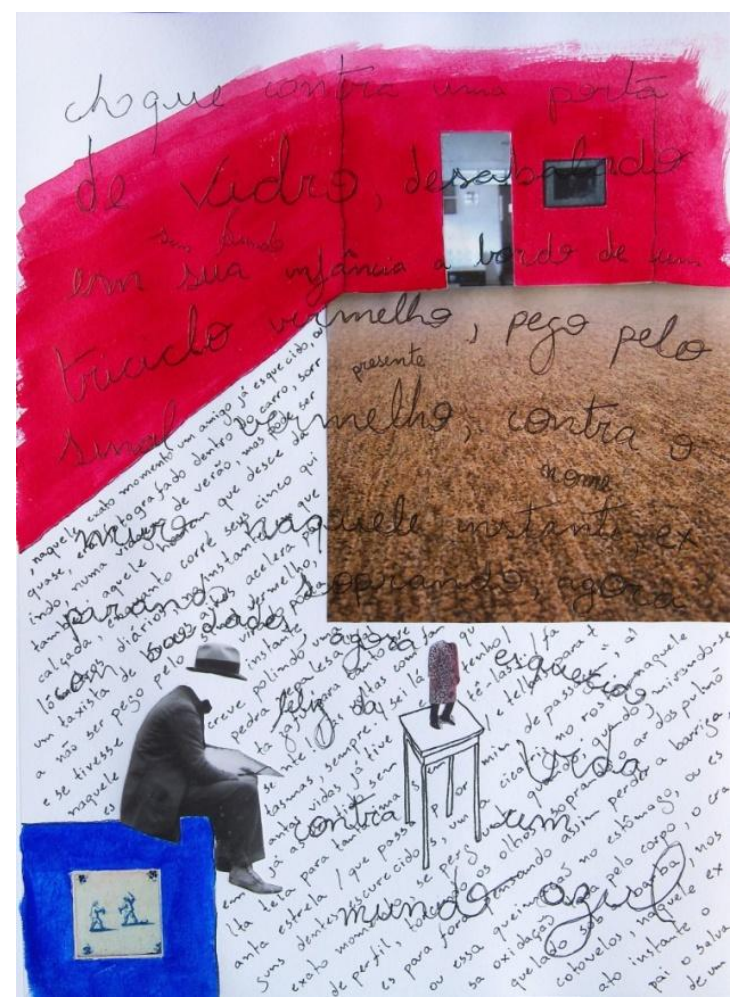

poeta coveiro

Sobre o feltro verde, o poeta coveiro enterra a poesia. dispondo cartas sem ver a canastra real - o logro invencível dele o eu, terreno do artifício, desequilibra o reverso da palavra vida.

Dois de paus ali parado, poeta boiteaux, fala com deuses cansados enquanto tudo morre a sua volta. 


\section{Zanga}

Dona Lírica irritada

Diz ao poeta:

Vc me exasperou, me exasperou... ${ }^{3}$ "Joelha e me peça perdão, joelha" 


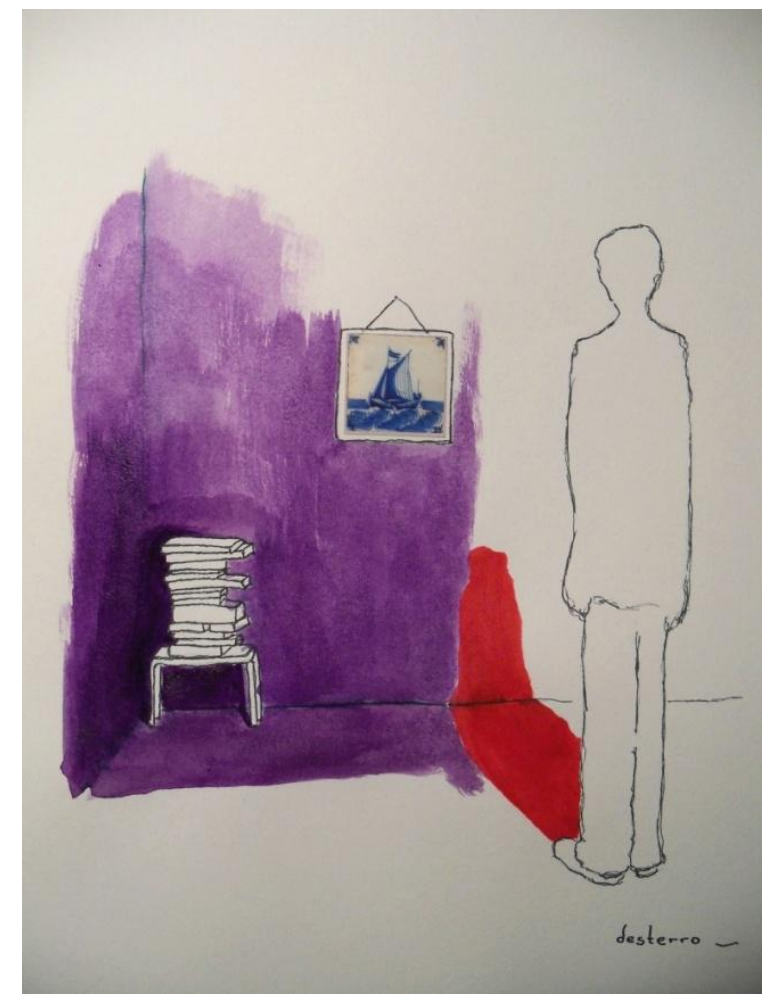

\section{A Vingança da Lírica}

Patos voam no verso de um fantasma.

Raízes soltaram-se do solo.

Pulso, punho, soco no estômago.

Mallarmé, o afogado, rompeu o pacto do poeta lírico.

O verso pur si muove...

Ao longe um leque farfalha música dos espaços infinitos. nos confins do eu, teatro mambembe. 
Exílio

êxodo de si

esqueleto esvaziado

sopro interrompido...

No céu da boca da linguagem, céu da poesia.

o chocalhar dos ossos, sacrílegos dados,

um tombo,

um túmulo

insânia exangüe,

$O$ resto é o silêncio

do poeta morto... 


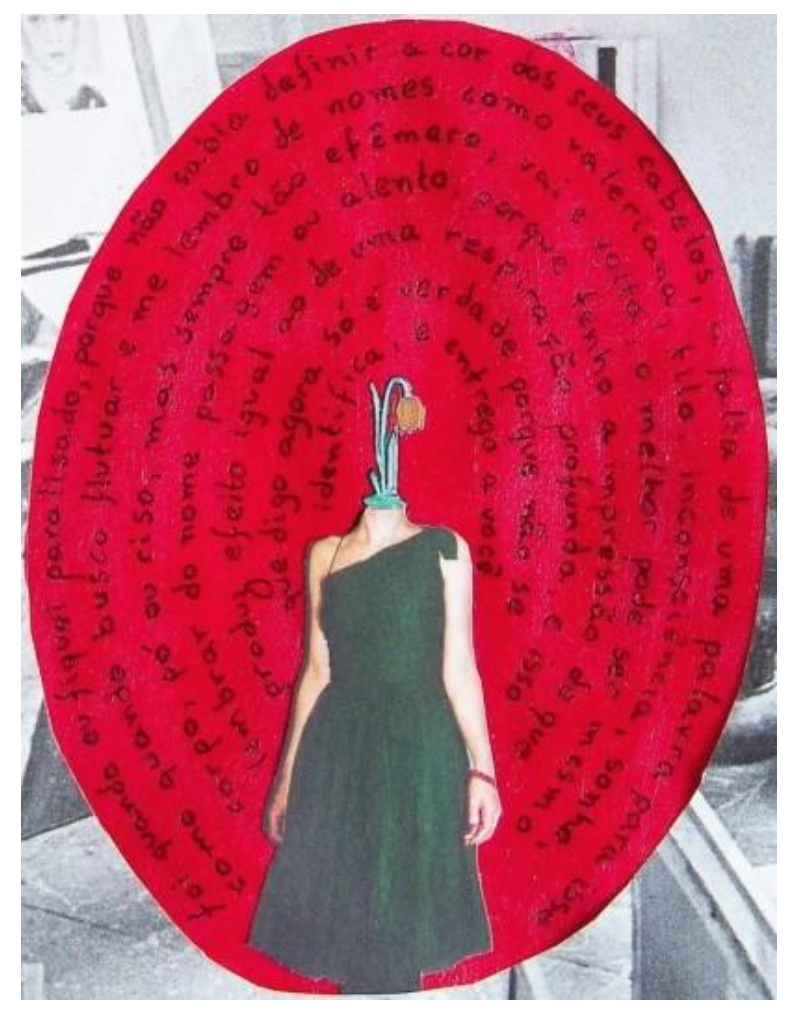

\section{A ostra tentadora}

Desde Mallarmé inaugurava-se

a Lírica sem poeta.

Motor louco

ostra absoluta

puro acaso

barco bêbado

a verdadeira vida ausente, infraleve e perturbadora vontade transtornada

assombro

ímã, romã

errática, enigmática

apnêica,

fruto da terra

estrela de pontas agudas 
morte do símbolo

soltura do imaginário

dança

de beija-flor...

jubilação nua

livre de toda amargura

khôra, buraco vago

onde se dissolve a realidade

o sexo

o nexo.

Três vezes vencedora

ergue-se a Lírica soberana sobre o corpo do morto. 


\section{APENSO}

a máquina à revelia, novíssima qual prometeu acorrentado no nada.

enquanto isso uma sombra se move, grave, entre

triste e lutadora

quer colar-se

a esse buraco

no centro do colar.

não

cala.

(artur de vargas giorgi) 


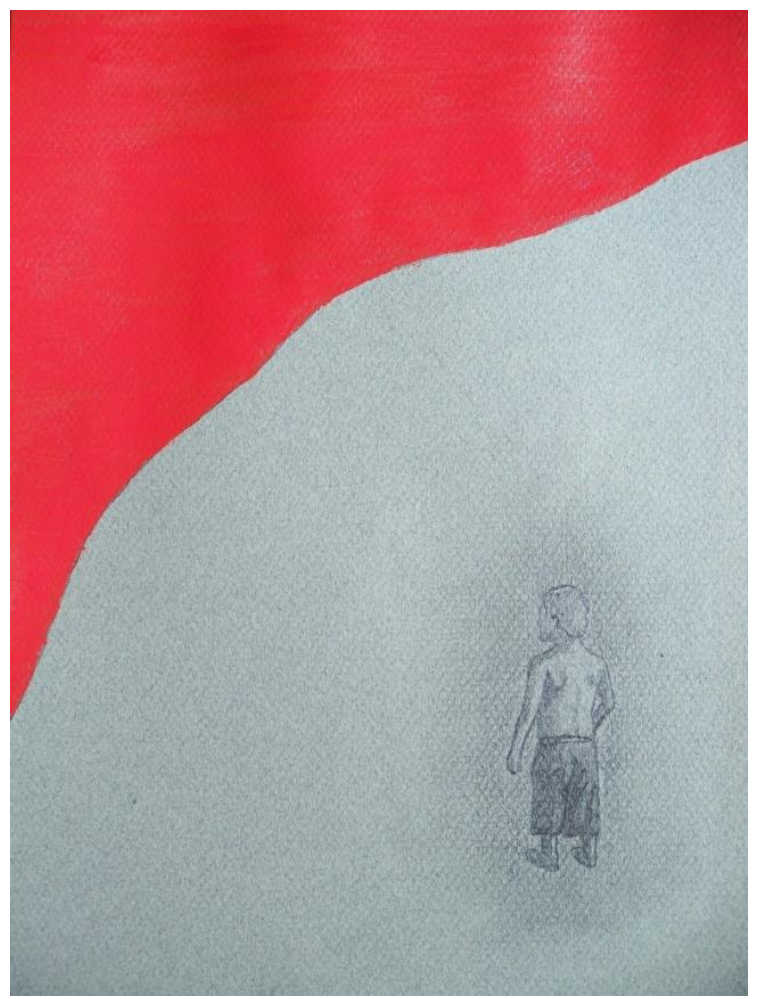

ninguém concentrado em mim

desenraizo, vou até ali solta, voo sem asas,

os emblemas vazios, poesia

pouca, marco avançado

do que não faz diferença.

(ana chiara) 